\title{
Drivers for the deepening of severe European windstorms and their impacts on forecast quality.
}

\author{
Jennifer S. R. Pirret ${ }^{a, b *}$, Peter Knippertz ${ }^{a, c}$ and Tomasz M. Trzeciak ${ }^{a, d}$ \\ ${ }^{a}$ School of Earth and Environment, University of Leeds, Leeds, UK \\ ${ }^{b}$ Met Office, Aberdeen, UK \\ ${ }^{c}$ Institute of Meteorology and Climate Research, Karlsruhe Institute of Technology, Karlsruhe, Germany \\ ${ }^{d}$ Met Office, Exeter, UK. \\ *Correspondence to: jennifer.pirret@metoffice.gov.uk
}

\begin{abstract}
European windstorms are a high-impact weather phenomenon, regularly inflicting substantial damages, both human and economic. This study examines a set of objectively selected intense European windstorms from the 1979-2015 period using re-analysis and forecast products from the European Centre for Medium-Range Weather Forecasts (ECMWF). The storms are first categorised with respect to their diabatic relative to the baroclinic contribution to deepening using the pressure tendency equation and additionally with respect to their track relative to the jet stream as the large-scale element controlling storm deepening and propagation. As expected, baroclinic processes dominate the majority of storms, such that deepening is closely related to warm advection ahead of the cyclone centre. Contributions from diabatic processes vary strongly and exceed those from horizontal temperature advection in 10 out of the 58 cases with values of up to $60 \%$. Remarkably in several cases, planetary waves in the stratosphere appear to facilitate cyclogenesis, but can also act to oppose deepening in a few cases. The diabatic contribution is significantly correlated to the time a given storm spends on the equatorward side of the jet, where there is greater potential for diabatic processes in the warm, moist air. In terms of forecast quality, and consistently with previous studies, the storms' core pressure is generally underestimated and storms tend to be too slow and shifted south in the forecast, particularly for longer lead times. These biases, however, reduce markedly with the improvement of the operational system over time. There is no systematic dependency of forecast behaviour on diabatic contribution or track relative to the jet. In the future, some of these analyses should be repeated with homogeneous reforecast data to better substantiate these findings.
\end{abstract}

Key Words: baroclinicity; diabatic processes; stratosphere; midlatitude cyclone; pressure tendency; jet stream; storm severity index; windstorms

Received...

1. Introduction

Windstorms associated with cool-season cyclonic disturbances are an important natural hazard for Europe. As high-impact weather, windstorms regularly cause fatalities and substantial economic damage (Munich Re NatCatSERVICE (2015); Table

1). Destructive examples from recent decades include the storm series of 1990 and 1999, or more recently storms Kyrill, Klaus

This article has been accepted for publication and undergone full peer review but has not been through the copyediting, typesetting, pagination and proofreading process, which may lead to differences between this version and the Version of Record. Please cite this article as doi: 10.1002/qj.2923

This article is protected by copyright. All rights reserved. 
and Xynthia. Forecasting such windstorms accurately means that weather warnings can be issued and the population can take action to mitigate damage and avoid fatalities.

The dynamics of strong cyclones affecting Europe has been a subject of scientific studies since the early days of meteorology (e.g. Bjerknes and Solberg 1922). The most crucial ingredient for their development is baroclinic instability, which is related to the arge-scale temperature difference between subtropical and polar latitudes and thus the strength of the jet stream (e.g. Eady 1949).

For the most intense cyclones that affect Europe, initiation often occurs in the western North Atlantic, followed by an eastward or north-eastward movement of the system (e.g. Wang and Rogers 2001; Allen et al. 2010). Deepening is usually most rapid as the cyclones cross the jet stream (Rivière and Joly 2006a,b), making s an important phase in the development of severe European windstorms. Diabatic effects can also modify storm development (e.g. Posselt and Martin 2004; Čampa and Wernli 2012; Ludwig et al. 2014), particularly latent heat release in the associated frontal cloud bands (e.g. Emanuel et al. 1987; Whitaker and Davis 1994; Ahmadi-Givi et al. 2004; Willison et al. 2013). In fact in case of so-called diabatic Rossby waves, the development of a cyclone, at least in the early stages, depends critically on diabatic factors (Parker and Thorpe 1995; Wernli et al. 2002; Moore and Montdomery 2004, 2005; Boettcher and Wernli 2013).

(1)

Different approaches have been used to determine the relative Importance of these factors on the deepening of cyclones. These nclude: (a) sensitivity studies using numerical models with suppressed latent heating (e.g. Stoelinga 1996; Odell et al. 2013; Lydwig et al. 2015); (b) existence of high- $\theta_{e}$ air near the cyclone centre (Liberato et al. 2013; Fink et al. 2012, hereafter FPPK12); (c) trajectory analysis indicating involvement of moist tropical airmasses in the cyclonic circulation (Knippertz and Wernli 2010). More recently, FPPK12 developed a new approach based on the pressure tendency equation (PTE). This allows diagnosis of how much diabatic effects contribute towards the deepening of a storm, relative to the contributions from horizontal temperature advection and temperature changes in the upper and middle atmosphere (Section 2.4). FPPK12 examine a small number of cases but no
Midlatitude cyclones are systematically forecast to be less intense and slower than in reality by numerical weather prediction (NWP) systems (Froude et al. 2007; Froude 2009). One potential source of this error may be diabatic processes, due to their nonlinear behaviour and small-scale structures. In fact it has been shown that the coarse resolution used for climate projections and seasonal forecasts appears to lead to underestimation of cyclone intensification, because crucial diabatic processes (e.g. rainfall along fronts) and their impacts on the generation of potential vorticity are not well represented (Jung et al. 2006; Willison et al. 2013). However, diagnosing this effect quantitatively is challenging and requires new approaches as for example shown by Trzeciak et al. (2016), who applied the PTE tool developed by FPPK12 to NWP experiments with climate models.

The aim of this paper is twofold: firstly, the PTE approach by FPPK12 will be applied to a much larger ensemble of 58 severe European cyclones that were objectively selected from reanalysis data generated by the European Centre for MediumRange Weather Forecasts (ECMWF) to give a statistically more robust idea about what processes are important to deepen the most severe cyclones. Secondly, evidence for a systematic influence of the type of storm on forecast quality will be sought, using forecast data from ECMWF for the 39 storms that occurred since 1990.

The paper is structured as follows. Section 2 provides details on the employed data and methods used to track and select storms, as well as on the PTE diagnostic. Results from the latter will be presented in Section 3 in the form of case studies and statistical analyses, alongside an examination of the storms tracks relative to the jet stream. Section 4 then discusses the impact of storm type on forecast quality followed by discussion and conclusions in Section 5.

\section{Data and Methods}

\subsection{ECMWF analyses and forecasts}

The ERA-Interim reanalysis from ECMWF (Dee et al. 2011) was used at 6-hourly resolution for a large part of this work, with resolution T255 L60. Forecast data were taken from the comprehensive operational archive of ECMWF, as re-forecasts are still only available for a subset of forecast days, making a detailed 


\begin{tabular}{|c|c|c|c|c|c|c|}
\hline \multirow[t]{2}{*}{ Storm Name } & \multirow[t]{2}{*}{ Date } & \multirow[t]{2}{*}{ SSI } & \multirow[t]{2}{*}{ Min. Pressure } & \multirow[t]{2}{*}{ People Killed } & \multicolumn{2}{|c|}{ Damage (Million US\$) } \\
\hline & & & & & At the time & Apr 2015 \\
\hline Cosina & $1979-12-15$ & 24.4 & 969.4 & & & \\
\hline Regina & 1980-01-21 & 7.2 & 968.0 & 9 & 250 & \\
\hline Orelia & 1981-11-24 & 28.9 & 966.1 & & & \\
\hline Dec 1981 & $1981-12-30$ & 24.8 & 971.2 & & & \\
\hline Mar 1982 & 1982-03-11 & 14.0 & 967.6 & & & \\
\hline Zaide & 1982-11-07 & 20.8 & 952.5 & 12 & 350 & \\
\hline Pia & $1982-12-16$ & 7.7 & 940.6 & & & \\
\hline Lavinia & 1983-02-01 & 10.5 & 953.1 & 5 & & \\
\hline Pallas & 1984-01-03 & 8.0 & 956.5 & & & \\
\hline Umberta & 1984-01-13 & 16.7 & 942.8 & & & \\
\hline Helena & 1984-10-24 & 28.8 & 965.7 & & & \\
\hline Nov 1984 & 1984-11-24 & 26.8 & 953.5 & & & \\
\hline Jan 1986 & 1986-01-20 & 14.6 & 975.0 & & & \\
\hline Verena & 1986-12-19 & 14.6 & 968.7 & & & \\
\hline Constanze & $1987-03-27$ & 9.1 & 984.3 & & & \\
\hline Toska & $1987-10-15$ & 29.4 & 957.0 & 24 & 3265 & \\
\hline Jenufa & 1988-02-01 & 7.7 & 949.4 & & & \\
\hline Margot & 1988-02-09 & 11.1 & 943.8 & & & \\
\hline Daria & 1988-03-16 & 11.0 & 967.5 & & & \\
\hline Almut & $1989-02-25$ & 45.0 & 954.1 & & & \\
\hline Lydia & 1989-12-16 & 14.8 & 940.0 & & & \\
\hline Daria & $1990-01-25$ & 27.5 & 949.2 & 85 & 6860 & 15437 \\
\hline Nana & 1990-02-11 & 9.2 & 958.2 & 1 & 190 & 428 \\
\hline Vivian & $1990-02-27$ & 47.5 & 941.0 & 50 & 3230 & 7268 \\
\hline Wiebke & 1990-03-01 & 47.5 & 971.5 & 67 & 2260 & 5086 \\
\hline Udine & 1991-01-05 & 17.1 & 948.0 & 48 & 909 & 1860 \\
\hline Verena & 1993-01-14 & 8.5 & 972.8 & 6 & 385 & 720 \\
\hline Agnes & 1993-01-24 & 20.3 & 966.8 & & & \\
\hline Dec 1993 & 1993-12-08 & 10.1 & 959.3 & & & \\
\hline Urania & $1995-01-23$ & 9.7 & 959.2 & & & \\
\hline Silke & 1998-12-26 & 12.3 & 949.0 & & & \\
\hline Lara & 1999-02-05 & 15.8 & 949.9 & & & \\
\hline Anatol & 1999-12-03 & 18.9 & 955.9 & 27 & 2963 & 4635 \\
\hline Franz & 1999-12-12 & 8.1 & 973.0 & & & \\
\hline Lothar & $1999-12-26$ & 39.2 & 975.9 & 137 & 11350 & 17754 \\
\hline Martin & 1999-12-27 & 7.0 & 968.3 & 14 & 4100 & 6413 \\
\hline Kerstin & $2000-01-29$ & 8.0 & 941.3 & & & \\
\hline Rebekka & 2000-11-06 & 15.9 & 965.8 & & & \\
\hline Elke & $2000-12-08$ & 10.9 & 972.6 & & & \\
\hline Lukas & $2001-01-28$ & 7.7 & 993.3 & & & \\
\hline Pawel & 2002-01-01 & 8.1 & 989.2 & & & \\
\hline Jennifer & $2002-01-27$ & 14.7 & 953.4 & 17 & 150 & 223 \\
\hline Frieda & 2002-03-08 & 7.9 & 963.2 & & & \\
\hline Jeanette & $2002-10-27$ & 28.1 & 975.1 & 39 & 2531 & 3732 \\
\hline Erwin & 2005-01-09 & 29.2 & 960.9 & 16 & 5635 & 7779 \\
\hline Gero & $2005-01-12$ & 13.5 & 947.8 & 7 & 50 & 69 \\
\hline Cyrus & $2005-12-16$ & 8.1 & 975.1 & & & \\
\hline Hanno & 2007-01-14 & 13.5 & 970.6 & & & \\
\hline Kyrill & 2007-01-19 & 40.8 & 961.5 & 46 & 9010 & 11700 \\
\hline Emma & $2008-02-27$ & 35.7 & 974.7 & 13 & 1800 & 2233 \\
\hline Johanna & 2008-03-10 & 7.6 & 947.6 & & & \\
\hline Klaus & $2009-01-24$ & 54 & 965.8 & 28 & 5100 & 6119 \\
\hline Quinten & $2009-02-10$ & 8.5 & 975.7 & & & \\
\hline Xynthia & $2010-02-28$ & 14.7 & 968.5 & 64 & 6074 & 7282 \\
\hline Friedhelm & 2011-12-08 & 9.4 & 957.7 & & & \\
\hline Joachim & 2011-12-16 & 21.2 & 965.7 & & & \\
\hline Ulli & 2012-01-03 & 9.9 & 954.6 & & & \\
\hline Nicki & $2012-12-13$ & 9.4 & 951.3 & & & \\
\hline Xaver & 2013-12-06 & 21.6 & 961.5 & & & \\
\hline Dirk & 2013-12-24 & 15.1 & 931.7 & & & \\
\hline
\end{tabular}

Table 1. Selected storms in chronological order with maximum SSI, and the date on which maximum SSI occurred. Pressure refers to the minimum core pressure achieved by the storm during its lifetime. The names of the storms are obtained from Free University of Berlin charts where available. The value of SSI quoted is the maximum reached, during the time the storm was passing over Europe. Details of fatalities and estimated damage are provided based on data

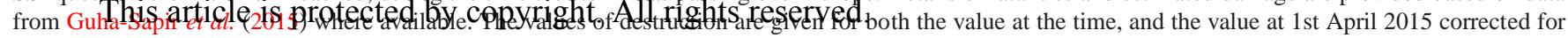
inflation (Office for National Statistics 2011) to ease direct comparison, when data is available. 
analysis of individual storms rather difficult. The disadvantage of using output from an operational system is that the model itself, the employed resolution and the data assimilation system improve over time. This is one of the reasons why forecasts are anlysed only for the 39 storms after 1st January 1990. This inhomogeneity in the data will have to be kept in mind when interpreting the results in Section 5. For our analysis both deterministic and ensemble forecasts were obtained at the best resolution available at the time of each storm (Table 2). The control member of the ensemble forecast was analysed in two ways: as a comparison for deterministic forecast at a lower resolution, and alongside the other members. Due to the increase in the number of ensemble members from 32 to 50 in December 1997, ensemble data have only been analysed for storms after this date (i.e. 28 out of 39 ), as there is a known link between the number of forecast members and forecast quality (Buizza and Palmer 1998). Futhermore, while reanalyses do assimilate observational data, parametrisation schemes are used to represent diabatic processes, which does result in biases in moist cloud processes in extratropical cyclones (Naud et al. 2006, 2014).

\begin{tabular}{|l|l|r|}
\hline \multicolumn{3}{|c|}{ Operational Forecasts } \\
\hline$T 106$ & $L 19$ & 5 \\
\hline$T 213$ & $L 31$ & 4 \\
\hline$T_{L} 319$ & $L 31$ & 2 \\
\hline$T_{L} 319$ & $L 60$ & 5 \\
\hline$T_{L} 511$ & $L 60$ & 10 \\
\hline$T_{L} 799$ & $L 91$ & 6 \\
\hline$T_{L} 1279$ & $L 91$ & 7 \\
\hline Total & & 39 \\
\hline
\end{tabular}

\begin{tabular}{|l|l|r|}
\hline \multicolumn{3}{|c|}{ Ensemble Control } \\
\hline$T_{L} 159$ & $L 40$ & 5 \\
\hline$T_{L} 255$ & $L 40$ & 10 \\
\hline$T_{L} 399$ & $L 62$ & 6 \\
\hline$T_{L} 639$ & $L 62$ & 7 \\
\hline Total & \multicolumn{2}{|r|}{28} \\
\hline
\end{tabular}

Table 2. Number of selected storms with forecasts at each resolution. $T$ and $T_{L}$ refer to horizontal resolution in terms of truncated wavenumbers, and $L$ refers to the number of vertical levels.
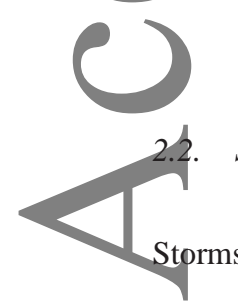

\section{Storm selection}

Storms were selected based on their potential to inflict damage on Europe using the Storm Severity Index (SSI) developed by Klawa and Ulbrich (2003) and Leckebusch et al. (2008). The SSI uses the cube of the wind speed above the local 98th percentile of wind climatology (1979-2015), giving an indication of potential damage based on meteorological variables. The SSI was calculated from ECMWF ERA-Interim 10m wind data for each grid point in the area 40 to $60^{\circ} \mathrm{N}$ and $10^{\circ} \mathrm{W}$ to $20^{\circ} \mathrm{E}$, which
Atlantic Ocean and Mediterranean Sea. These values were then summed and ranked by the total value. SSI is a useful measure of potential damage that a storm can inflict, because it is based on wind power. However, it is sensitive to the local climatology, orography and land-sea distribution. Furthermore, boundary layer processes affect the strength of the wind at $10 \mathrm{~m}$, with factors such as SSTs (Sampe and Xie 2007) and atmospheric stability (Booth et al. 2010) having significant influence.

Out of the top 220 SSI values, 93 occurred within 24 hours of a meteorological situation with a higher value of SSI and were therefore excluded as duplicates. A further 67 cases were excluded, because they were related to weather phenomena other than midlatitude Atlantic cyclones, identified through a subjective analysis of weather charts and horizontal distributions of SSI. These weather phenomena were: Mediterranean cyclones (20), polar lows (3), large pressure gradients at the fringe of strong highpressure systems (42), and orographic effects (3). The remaining 60 storms finally selected are listed in Table 1 . To ensure that the correct track had been selected by the storm tracker, the tracks were subjectively compared to the evolution of each storm in synoptic charts, including those from the Free University of Berlin that include storm names.

All the storms in the list have the potential to inflict damage, given values of the SSI between 7 and over 50 (Table 1). Table 1 also includes details (where available) for those storms that have caused fatalities and economic damage. The list features many famous storms, including two destructive storm series from January to March 1990 (Daria, Vivian, Wiebke) and December 1999 (Anatol, Lothar, Martin). Several of these storms have already been analysed in detail in terms of their synoptic evolution, dynamics and impacts, e.g. Vivian (Goyette et al. 2001), Lothar (Wernli et al. 2002; Rivière et al. 2010), Kyrill (Fink et al. 2009; Ludwig et al. 2015), Klaus (Liberato et al. 2011; Rivière et al. 2015), Xynthia (Rivière et al. 2012; Ludwig et al. 2014) and Friedhelm (Rivière et al. 2015; Vaughan et al. 2014). Given the damage associated with these storms of sometimes more than 10 billion US\$ (adjusted to April 2015) and the number of deaths (Table 1), it is essential that NWP models reproduce them satisfactorily in order to allow reliable warnings to be issued and mitigating action to be taken. 


\subsection{Storm tracking}

The storms were tracked using the method described in detail by Trzeciak et al. (2016). The first steps are to identify a minimum in mean sea-level pressure (MSLP) and an associated maximum in the vorticity at $850 \mathrm{hPa}$. Identification is then repeated at the next time step. Two points are joined together, if the MSLP fields for the $10^{\circ}$ longitude by $5^{\circ}$ latitude boxes around the identified cyclone centres positively correlate and if the distance between the two points does not exceed a threshold. The limit on distance between the points considers for the value of the vorticity, because more intense storms (i.e. those with higher vorticity) tend to move more quickly. Identification is then performed on subsequent time steps, with the same criteria for joining the points together but with an additional requirement that prevents tracks turning suddenly, which is not commonly observed for midlatitude cyclones. Tracks are scored based on length, smoothness and the degree of correlation between the pressure fields at subsequent tithe steps.

Once the storms had been tracked in ERA-Interim reanalysis 4 data, this process was repeated for ECMWF forecasts. The tracker has an additional feature whereby a reference track can 1 be provided, which in this case was the track in the reanalysis data. The forecast track closest to the reanalysis track was output first, which allowed the tracks to be matched easily. This is a particularly useful feature for storms that occur in quick succession (e.g. Vivan, Wiebke; Lothar, Martin), where the highest-scoring track could match a different storm. Providing a reference track meant forecast tracks were compared to the reanalysis track of the correct storm.

Once the storms were tracked, they were also categorised in terms of their interaction with the jet stream as the large-scale element controlling storm deepening and propagation. This was based on the $300 \mathrm{hPa}$ wind speed with no filtering applied, because the two-way interaction between the storm and the jet is not the focus of this paper. Charts similar to those shown in Figure 3 (left panels) were made, which slice the wind field in meridional sections along the track of the storm as in FPPK12. When the jet streams of all the storms are studied (not shown), four categories
- Edge: these storms do not cross the jet stream, but rather move along the poleward edge of the area of strong winds, sometimes in connection with a larger wave on the jet.

- Split: these storms are associated with more than one, zonally separate wind speed maxima, and cross at least one of them.

- Cross Early: these storms have only one jet stream, which they cross relatively early in their lifetime.

- Cross Late: these storms cross a single jet stream relatively late in their lifetime.

Determining the categories was predominantly done subjectively, through examination of charts for each storm. Distinction between early and late crossing was aided by computing the percentage of storm lifetime spent on each side of the jet stream. If this was less than $35 \%$, then the storm was deemed to cross early; greater than $35 \%$ meant the storms crossed the jet later. This percentage was less than one half, because the storm tracker is biased towards the later part of the storms' tracks, as it retains storms undergoing cyclolysis but does not identify them until cyclogenesis is well underway.

\subsection{PTE Analysis}

Generally speaking the main contributors to the deepening of cyclones are baroclinic conversions (transport of warm air upwards and polewards and transport of cold air equatorwards and downwards) and diabatic processes (latent heating, radiation, surface fluxes). The PTE approach taken by FPPK12 allows diagnosis of these contributions. To achieve this, the PTE is re-formulated from the classical mass-based version using virtual temperature, $T_{v}$, as the main variable (see FPPK12 for details). Essentially, the tendency of surface pressure (hereafter dPressure) then equals the vertical integral of the time change in $T_{v}$ from the surface to an upper boundary (dTemp). Column warming (cooling) is associated with pressure fall (rise). To close the equation correction terms for mass loss (gain) through precipitation (evaporation) $(E P)$ and for geopotential tendencies at the upper boundary $(d P h i)$ need to be taken into account, which are usually small (see discussion in Knippertz et al. (2009)). Any remaining Residual is an indication of errors due to vertical integration, using finite differences or model errors (Knippertz 
et al. 2009; Trzeciak et al. 2016, FPPK12). Finally the $d T e m p$ term can be split into contributions from horizontal temperature advection (horiz), vertical motion (vert) and diabatic heating (diab, diabres). The two different names for the diabatic term are motivated by the fact that some datasets contain explicit heating fields (diab), while others do not and therefore only allow the computation of a residuum (diabres). Here we use diabres as in FPPK12. A caveat of this approach is that these terms cannot be tryly considered independent, as diabatic processes such as latent heat release depend on the vertical motion of the air; however, a diagnostic tool, it can still be used to compare the different prbcesses that contribute to cyclonic deepening.

1

For each 6-hourly time step in the tracks identified in ERAInterim using the method described in Section 2.3, a $3^{\circ} \times 3^{\circ}$ box aching from the surface to $100 \mathrm{hPa}$ is centred on the cyclone position and the PTE is evaluated for this box using ERA-Interim on forecast model data for the 6 hours preceding the arrival of the cyclone centre. Around $50^{\circ} N 3^{\circ} \times 3^{\circ}$ corresponds to about $210 \mathrm{~km} \times 330 \mathrm{~km}$. Assuming a typical propagation speed of an intense west-east moving storm of $70 \mathrm{kmh}^{-1}$, a system crosses about 6 degrees longitude in a given 6-hour period. In such a) case, the western boundary of the $3^{o} \times 3^{o}$ box considered here falls exactly in the middle between the cyclone positions the beginning and end of the 6-hour interval. The method described here therefore focuses on the processes that take place downstream of the cyclone centre (i.e. ahead of the storm, where the pressure is falling) to create the surface pressure fall during the approach of the system in a mixed Lagrangian-Eulerian framework. A much smaller box would give too much weight to meteorological fields far away from the cyclone centre in cases of fast moving systems. On the contrary, a larger box may include to $\rho$ much information from the original position of the cyclone in case of slow-moving systems. The choice of the upper boundary of $100 \mathrm{hPa}$ implies that the $d P h i$ term is evaluated at this level.

FPPK12 already applied this method to some of the storms under consideration here showing that (a) dTemp clearly dominates all other terms during the main deepening phase, (b) horiz and diabres contribute to deepening while vert instigates pressure rise through adiabatic cooling, (c) relative contributions This article is protected by copyright. All rights reserv from diabres vary strongly from storm to storm with Xynthia,

Lothar and Klaus showing large values.

\section{Results from the PTE analysis}

\subsection{Example cases}

Figure 1 shows examples of the contributions made by each term of the PTE to the change in pressure during the lifetime of storms Friedhelm (6 - 15 December 2011) and Joachim (12 - 22 December 2011), respectively. The bars below the zero line are showing processes that contribute to storm deepening and those above the line contribute to filling, similar to the figures in FPPK12.

Both storms undergo a phase of rapid increase in deepening, with $d$ Pressure values reaching less than $-20 \mathrm{hPa}$ per $6 \mathrm{~h}$ (black lines in Figures 1a and 1b), followed by a sharp decrease and several-day period with small and often positive dPressure. The deepening of both storms is mainly due to $d T e m p$ (red bars in Figures 1a and 1b), as is the case with all of the selected storms (not shown). A large difference between Friedhelm and Joachim is the contribution from $d P h i$ (green bars in Figures 1a and 1b). This indicates that processes in the stratosphere (i.e. above $100 \mathrm{hPa}$ ) support deepening moderately in the former case but counteract deepening substantially in the latter case during the most intense phases, while both storms show generally positive $d P h i$ towards their decay. Contributions from EP are nonnegligible during the first intense phase, particular for Joachim, and then remain small thereafter (blue bars in Figures 1a and 1b). Similar behaviour can be seen for the other selected storms (not shown, see time-integrated values in the third column of Table 3). It is also interesting to note that storm Joachim has relatively large Residual terms (grey bars in Figures 1a and 1b) at the beginning of the deepening phase in stark contrast to Friedhelm. The reason for this is unclear.

As explained in Section 2.4, the term dTemp (red bars in Figures $1 \mathrm{a}$ and $1 \mathrm{~b}$ and black lines in Figures 1c and 1d) can be divided into horiz, vert and diabres. In agreement with FPPK12, rising motions and associated adiabatic cooling to the east of the approaching storm works to increase $d T e m p$ throughout most of the storm development for practically all selected storms (blue erved. 
(a) Friedhelm

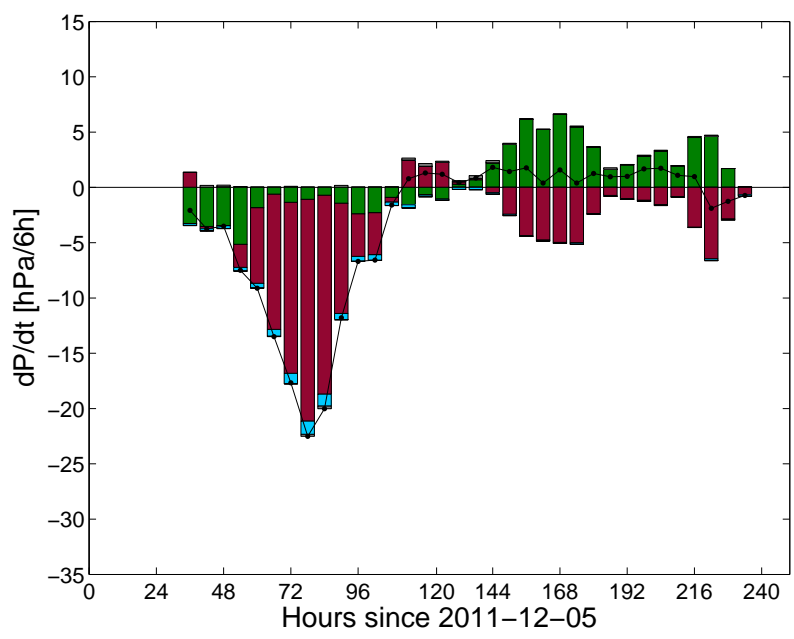

(b) Joachim

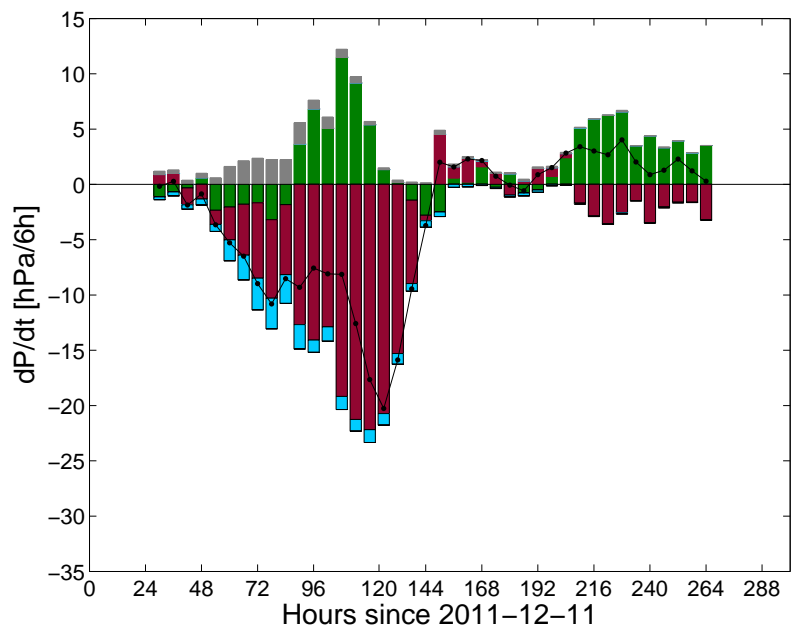

\section{dPhi}

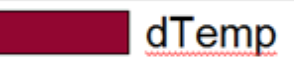

(c) Friedhelm

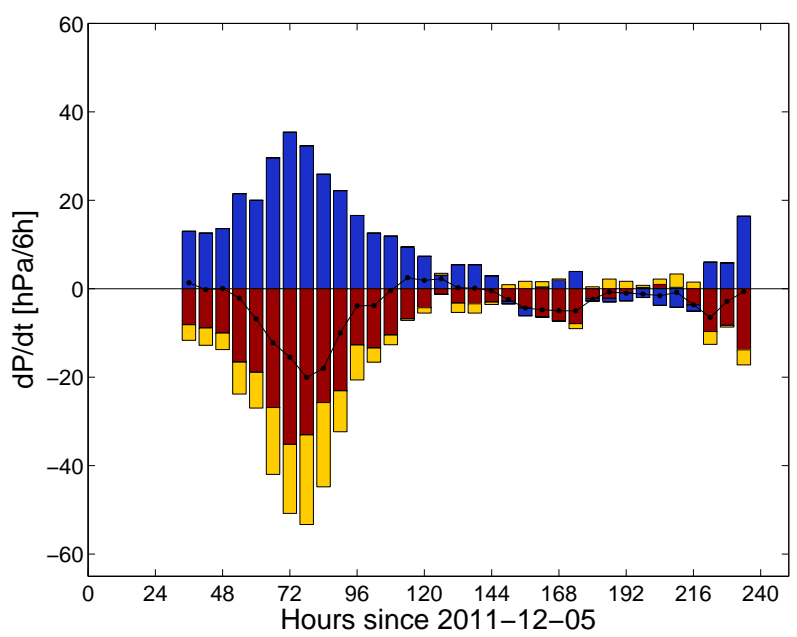

(d) Joachim

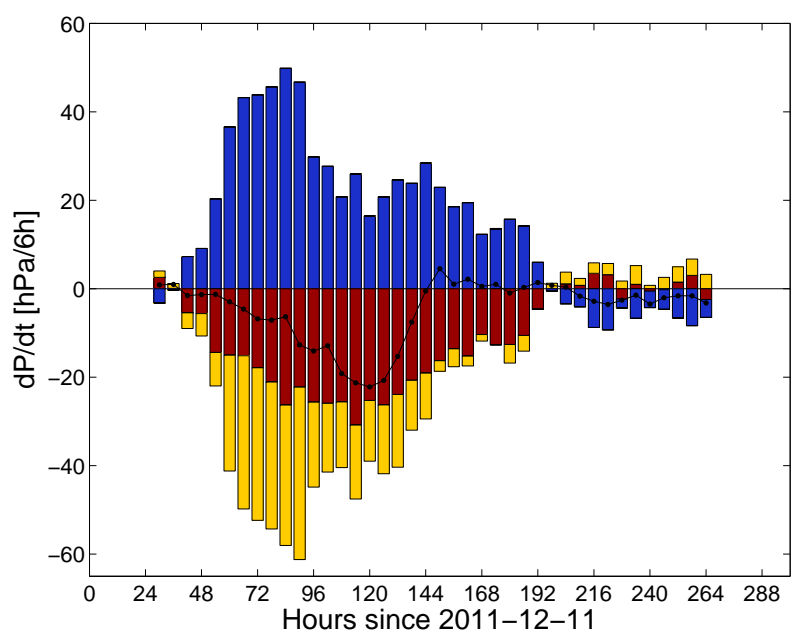

horiz

vert

diabres

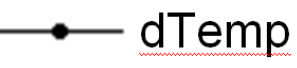

C

Figure 1. PTE analysis (see section 2.4 for an explanation) of storm Friedhelm, dominated by horizontal temperature advection (left panels) and storm Joachim, where diabatic processes are the main contributor to deepening (right panels). Top panels show the overall PTE budget, while bottom panels show the contributions of the individual components to the virtual temperature term. Yellow spots indicate time of maximum SSI. Calculated from ERA-Interim data using the method from Fink et al. (2012).

bars in Figures 1c and 1d). Horizontal temperature advection and diabatic processes (red and yellow bars, respectively, in Figures 1c and 1d) mainly work to deepen the storms, apart maybe from the decaying stages towards the end of a storms lifetime. Friedhelm's deepening is mainly due to horizontal temperature advection, although there is a substantial contribution from diabatic processes when the storm is rapidly deepening (Figure 1c, 60-80 hours). For Joachim relative contributions from diabres are generally larger and lasting through a longer period This article is protected by copyright. All rights reserved. of the deepening, consistent with the larger EP values evident from Figures 1a and 1b. The evolution of Joachim also shows a certain anticorrelation between vert and diabres, as the latter is dominated by latent heat release, which in turn depends on vertical motion.

In Figure 2, the examples of storms Wiebke (25 February - 4 March 1990) and Emma (27 February - 3 March 2008) illustrate how in some cases processes reaching into the stratosphere (i.e. above $100 \mathrm{hPa}$ ) can have a profound effect on the depth of 
the cyclone as quantified by the term $d P h i$. Despite being a relatively destructive storm (Table 1), Wiebke never reached dPressure values below $-14 \mathrm{hPa}$ per $6 \mathrm{~h}$ with overall moderate contributions from $d T e m p$ (Figure 2a). Instead, geopotential tendencies at the $100 \mathrm{hPa}$ level make a substantial contribution to the pressure fall at the surface during most of the active phase of the storm, suggesting that processes in the stratosphere have played a role to create this storm. Interestingly, Emma, also a destructive storm (Table 1), shows the opposite behaviour with $d P h i$ opposing deepening throughout the entire lifetime of the storm counteracting some of the large $d T e m p$ values that kept the storm developing into a severe cyclone despite unfavourable conditions in the stratosphere (Figure 2b). Some first case studies suggest that mobile planetary waves in the stratosphere are important to create such large $d P h i$ terms (also mentioned for the Braer storm discussed by Odell et al. (2013)), but the exact mechanisms are not clear and deserve future study. The main consequence for further investigation is that in some cases, $d P h i$ cannot be neglected when disentangling contributions to storm deepening.

\subsection{Statistical analysis}

1

A more quantitative approach was developed, which considers the percentage contribution of each term towards the total deepening, accrued over the deepening phase of the storm (i.e. the period when dPressure is negative, see Figures 1 and 2 for examples). The strength of this method is that it gives one numerical value for each storm and process independent of the storms lifetime, deepening rate or resulting minimum core pressure, thereby making storms more comparable. The main drawback is that this method does not give an idea of how the processes evolve throughout the lifetime of the storm. For example, if diabatic processes are important initially, but horizontal temperature advection takes on a greater role in the later stages of cyclogenesis, as hinted at by Figure 1d and discussed in depth for storm Lothar by Wernli et al. (2002).

The results of this calculation are shown in Table 3 in order of descending diabres percentage contribution. Note that two PTE terms are not included in Table 3, due to their small contribution value of percentage contribution to deepening of $0.10 \%$ ), which points to the overall quality of the PTE closure as computed here; and the vert term that mainly contributes to weakening storms (see examples in Figures 1 and 2). Note also that the dPhi term has been set to zero in Table 3, where the overall contribution is positive (i.e. for Emma). For the other storms, the $d P h i$ contribution varies strongly, exceeding $30 \%$ in the cases of Almut and Pallas with 20 of the 60 storms having contributions of over $10 \%$. Contributions from $E P$ are typically between 1 and $4 \%$ for all storms with Xynthia's almost 5\% being an outlier. This storm took an unusually southern track from the subtropics and was therefore surrounded by quite warm and moist airmasses ( see FPPK12). Table 3 shows significant positive correlation between the $E P$ and diabres terms, with $\mathrm{R}=0.82$.

Comparing the contributions from horizontal temperature advection (horiz), here used as an indicator for baroclinic conversion, and diabatic processes (diabres), not surprisingly in most cases (48 out of 60 storms in Table 3) the percentage from horiz dominates. For further discussions in the following section we divide Table 3 into three groups: (a) top 20 diabatic contributions (i.e. diabres $>38.0 \%$ ), (b) bottom 20 diabatic contributions (diabres $<30.8 \%$ ), (c) intermediate storms (20 in total).

\subsection{Relationship to track characteristics}

The four jet categories discussed in Section 2.3 are illustrated by examples in Figure 3: (a) six storms that have a split jet (e.g. storm Xynthia in Figure 3a); (b) 20 storms that cross the jet relatively late (e.g. storm Jennifer in Figure 3c); (c) 15 storms that cross the jet relatively early (e.g. storm Kyrill in Figure 3e); and (d) 19 storms that never cross the jet stream but instead track along its poleward edge (e.g. storm Erwin in Figure 3g). See Tables 3 and 4 for details of all storm categories.

The right panels of Figure 3 show the $850 \mathrm{hPa} \theta_{e}$ field, which gives an indication of the temperature and humidity of the airmass, in which the storms are embedded. Higher $\theta_{e}$ values, meaning warmer and/or moister air, are found in the areas where storms Xynthia and Jennifer initially develop (Figures $3 b$ and d). In Xynthia's case, the storm stays in the high $\theta_{e}$ airmass for a long time, resulting in a record diabres contribution (Table 3). As served. 


\begin{tabular}{|c|c|c|c|c|c|c|}
\hline Storm Name & dphidt & EP & Horiz & Diabres & PTE Category & Jet Type \\
\hline Xynthia & 1.91 & 4.98 & 35.47 & 57.55 & Split & Diab \\
\hline Lothar & 11.14 & 3.62 & 29.98 & 54.76 & Cross late & Diab \\
\hline Helena & 4.25 & 4.25 & 39.02 & 52.43 & Cross late & Diab \\
\hline Klaus & 2.46 & 3.01 & 42.83 & 51.29 & Cross late & Diab \\
\hline Silke & 2.13 & 2.99 & 44.62 & 49.59 & Cross early & Diab \\
\hline Quinten & 11.62 & 3.35 & 36.19 & 48.77 & Cross late & Diab \\
\hline Toska & 3.68 & 3.16 & 45.16 & 47.97 & Cross late & Diab \\
\hline Gero & 7.68 & 2.46 & 41.89 & 47.60 & Split & Diab \\
\hline Udine & 7.90 & 2.52 & 41.26 & 47.60 & Cross early & Diab \\
\hline Jeanette & 8.22 & 3.57 & 39.78 & 45.67 & Edge & Diab \\
\hline Joachim & 2.43 & 3.27 & 49.00 & 44.90 & Cross late & Diab \\
\hline Verena (1993) & 4.29 & 2.62 & 48.12 & 44.84 & Cross late & Diab \\
\hline Elke & 1.09 & 3.82 & 50.89 & 43.86 & Split & Diab \\
\hline Mar 1982 & 12.00 & 2.54 & 42.62 & 42.27 & Cross late & Diab \\
\hline Lavinia & 14.91 & 2.54 & 40.57 & 41.73 & Edge & Diab \\
\hline Dec 1981 & 1.64 & 2.94 & 54.22 & 41.14 & Cross early & Diab \\
\hline Pallas & 37.31 & 2.08 & 1.45 & 40.59 & Edge & Diab \\
\hline Urania & 10.09 & 2.82 & 46.39 & 40.38 & Cross late & Diab \\
\hline Lydia & 10.26 & 2.34 & 49.01 & 38.29 & Edge & Diab \\
\hline Margot & 10.02 & 2.23 & 49.36 & 38.00 & Cross early & Diab \\
\hline 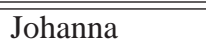 & $\overline{8.72}$ & "1.74 & $\overline{c 50.88}$ & $\overline{377.90}$ & Cross early & Intermediate \\
\hline Hanno & 14.46 & 2.20 & 45.66 & 37.68 & Cross late & Intermediate \\
\hline Umberta & 0.60 & 1.79 & 59.86 & 37.51 & Cross late & Intermediate \\
\hline Jenufa & 12.67 & 1.80 & 48.61 & 36.73 & Cross late & Intermediate \\
\hline Ulli & 7.94 & 2.42 & 52.43 & 36.72 & Cross late & Intermediate \\
\hline Wiebke & 18.55 & 1.92 & 43.03 & 36.13 & Cross late & Intermediate \\
\hline Jennifer & 5.60 & 2.55 & 55.69 & 35.95 & Cross late & Intermediate \\
\hline Lukas & 12.16 & 2.94 & 49.22 & 35.64 & Edge & Intermediate \\
\hline Vivian & 9.81 & 1.98 & 52.67 & 35.21 & Cross early & Intermediate \\
\hline Nov 1984 & 3.96 & 2.19 & 59.73 & 33.97 & Cross early & Intermediate \\
\hline Daria (1990) & 7.51 & 1.83 & 56.57 & 33.95 & Cross early & Intermediate \\
\hline Agnes & 5.21 & 2.41 & 56.39 & 33.82 & Edge & Intermediate \\
\hline Dec 1993 & 5.15 & 2.06 & 59.01 & 33.76 & Split & Intermediate \\
\hline Martin & 0.69 & 1.96 & 63.92 & 33.31 & Cross late & Intermediate \\
\hline Dirk & 9.78 & 1.95 & 54.87 & 32.90 & Cross early & Intermediate \\
\hline Anatol & 8.79 & 2.11 & 56.02 & 32.88 & Cross early & Intermediate \\
\hline Zaide & 7.07 & 3.07 & 57.15 & 32.55 & Cross early & Intermediate \\
\hline Xaver & 13.46 & 2.08 & 52.95 & 31.40 & Cross early & Intermediate \\
\hline Jan 1986 & 6.74 & 1.96 & 59.99 & 31.25 & Cross late & Intermediate \\
\hline Nana & 25.77 & 1.93 & 40.85 & 30.93 & Edge & Intermediate \\
\hline Cyrus & 8.80 & 1.67 & 58.56 & 30.83 & Cross late & 2 Horiz \\
\hline Orelia & 17.67 & 2.07 & 49.82 & 30.43 & Cross late & Horiz \\
\hline Erwin & 14.49 & 1.40 & 53.67 & 30.34 & Edge & Horiz \\
\hline Franz & 1.81 & 2.32 & 66.32 & 29.52 & Edge & Horiz \\
\hline Regina & 1.27 & 2.28 & 66.84 & 29.50 & Cross early & Horiz \\
\hline Friedhelm & 6.70 & 1.73 & 62.25 & 29.15 & Split & Horiz \\
\hline Kyrill & 2.42 & 1.74 & 66.61 & 29.07 & Cross early & Horiz \\
\hline Nicki & 7.24 & 1.74 & 63.33 & 27.53 & Edge & Horiz \\
\hline Constanze & 3.22 & 2.00 & 60.32 & 25.77 & Split & Horiz \\
\hline Emma & 0.00 & 1.41 & 73.80 & 24.72 & Edge & Horiz \\
\hline Verena (1986) & 17.98 & 1.24 & 56.97 & 23.56 & Edge & Horiz \\
\hline Lara & 29.25 & 1.35 & 43.42 & 22.30 & Edge & Horiz \\
\hline Frieda & 2.81 & 1.70 & 74.28 & 21.11 & Edge & Horiz \\
\hline Cosina & 17.64 & 2.24 & 59.32 & 20.74 & Cross late & Horiz \\
\hline Almut & 41.07 & 1.76 & 33.32 & 20.58 & Edge & Horiz \\
\hline Daria (1988) & 1.19 & 1.22 & 78.69 & 18.82 & Edge & Horiz \\
\hline Kerstin & 7.21 & 1.20 & 73.09 & 18.41 & Edge & Horiz \\
\hline Rebekka & 7.02 & 1.59 & 73.32 & 17.99 & Cross early & Horiz \\
\hline Pia & 6.07 & 1.43 & 75.53 & 16.93 & Edge & Horiz \\
\hline Pawel & 0.11 & 1.45 & 82.62 & 15.49 & Edge & Horiz \\
\hline
\end{tabular}

Table 3. Storms with percentage contribution (rounded to 2 decimal places) to deepening from selected terms of the PTE (see Section 2.4), ranked by diabatic terms (Diabres), calculated from ERA-Interim data using the method from Fink et al. (2012). The 20 storms with the highest contribution from Diabres are then categorised as diabatically-driven storms (Diab); the 20 with the lowest Diabres are driven by horizontal temperature advection (Horiz); and the remaining 20

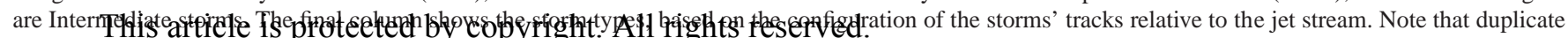
storm names also have their year specified. Further explanation is in Section 3.2 . 
(a) Wiebke

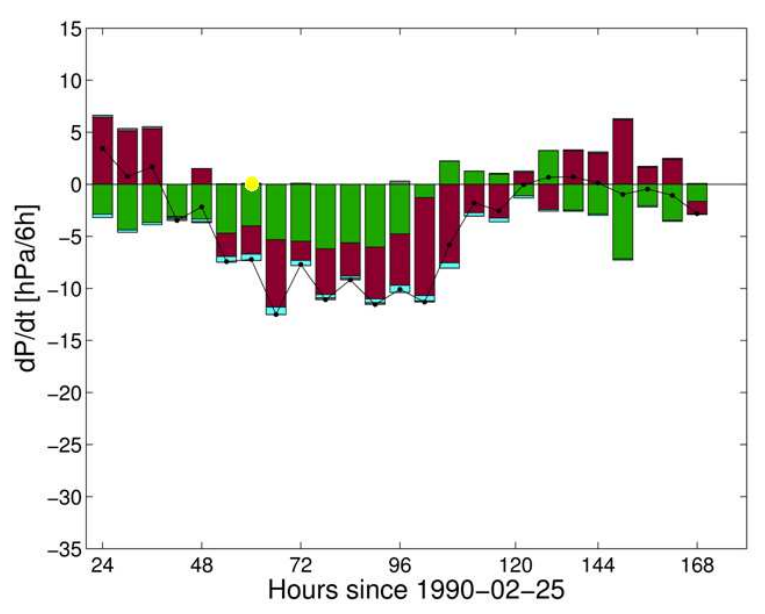

(b) Emma

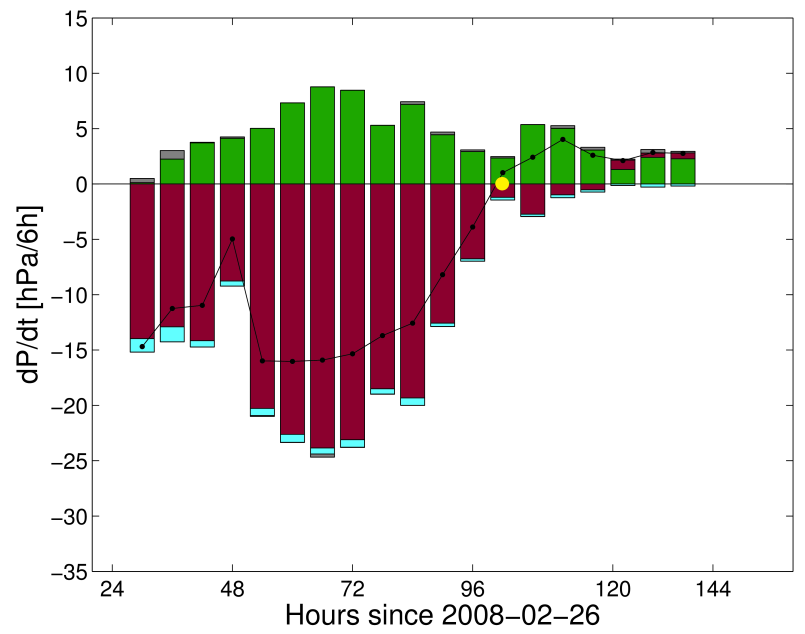

\section{dPhi}

dTemp

$\square$ EP

Residual

dPressure

Figure 2. As Figure 1(a,b), but for storms (a) Wiebke and (b) Emma.

Jennifer crosses the jet relatively late and then moves into cooler and probably drier air, the overall contribution of diabres is still in top half of storms. Kyrill in contrast crosses early and moves ostly through relatively low $\theta_{e}$ air (Figure $3 f$ ), associated with a A small contribution of diabres relative to horiz (Table 3), which is substantial in this case given the unusually strong jet (Figure 3e). 1 Erwin (Figure $3 \mathrm{~g}$ ) remains on the northern side of the jet stream tracking through low- $\theta_{e}$ air (Figure $3 \mathrm{~h}$ ) and so also has a much smaller contribution towards deepening by diabres compared to horiz (Table 3).

Table 4 shows a statistical evaluation of the different storm categories as listed in Table 3. It illustrates that there appears to be a link between certain categories: there are in total 19 storms of the edge category and those are clearly dominated by the 12 storms where the horiz term dominates the PTE. This is physically plausible, as storms that occur on the poleward side of the jet, often characterised by cooler and drier air and thus lower $\theta_{e}$ values (see right panels in Figure 3 for examples), are less likely to develop large contribution from latent heating and therefore tend to be driven by horizontal temperature advection. In contrast, the 20 storms that cross the jet stream late in their lifecycle tend to fall into the upper ( 9 storms) and middle terciles ( 8 storms) of the diabres term with only three storms being clearly dominated by plausible, as the equatorward side of the jet is characterised by high $\theta_{e}$ air. The cross-early and split-jet storm categories are less populated (15 and 6 storms, respectively) and relationships to diabres and horiz are less clear.

Statistical testing was performed to ascertain whether the distribution of storms amongst the categories is random. A $\chi^{2}$ test is not appropriate, because the population of the different categories is too small to be able to assume a normal distribution. Instead, a Fisher Exact test was applied (Rees 2001, Section 13.6) to Table 4 with the result that a purely random distribution was rejected at the $5 \%$ significance level $(p<0.03)$. To the best of our knowledge, this is the first time that a statistically significant relationship between the relative contribution from diabatic processes and the track of a cyclone relative to the jet has been demonstrated. Rivière et al. (2012) find that the time at which the storm crosses the jet is related to the horizontal gradient of the vertically averaged potential vorticity with a stronger gradient implying an earlier jet crossing, through an increased efficiency of energy dispersion downstream, reinforcing the downstream ridge and forcing the cyclone towards the pole, where according to our analysis the likelihood of diabatic contributions to deepening are reduced. The statistical testing performed in this paper indicates a significant link between the large-scale forcing and the local effects on a cyclones track. 
(a) Xynthia

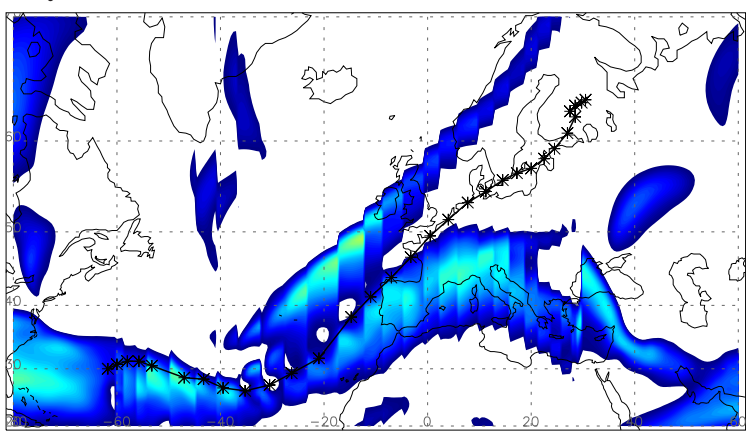

(c) Jennifer

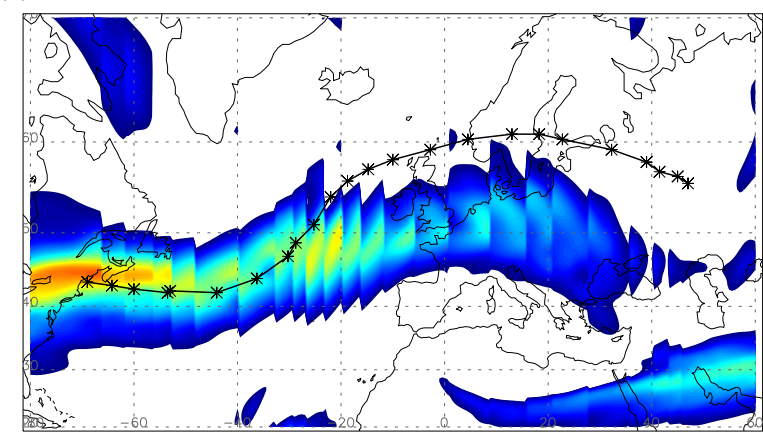

(e) Kyrill

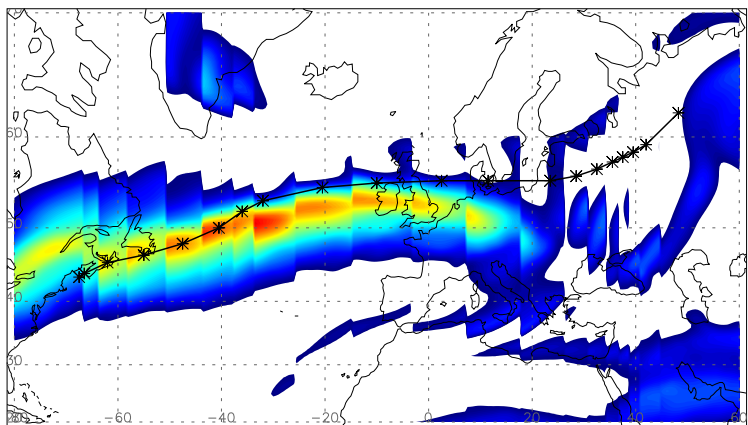

(g) Erwin

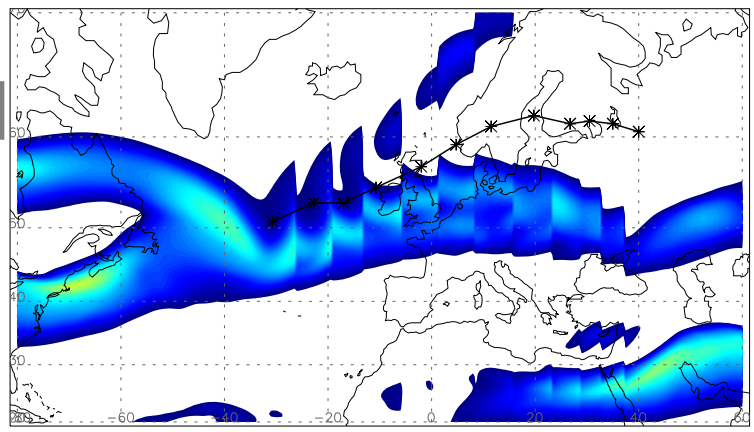

.

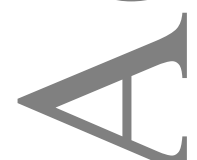

(b)

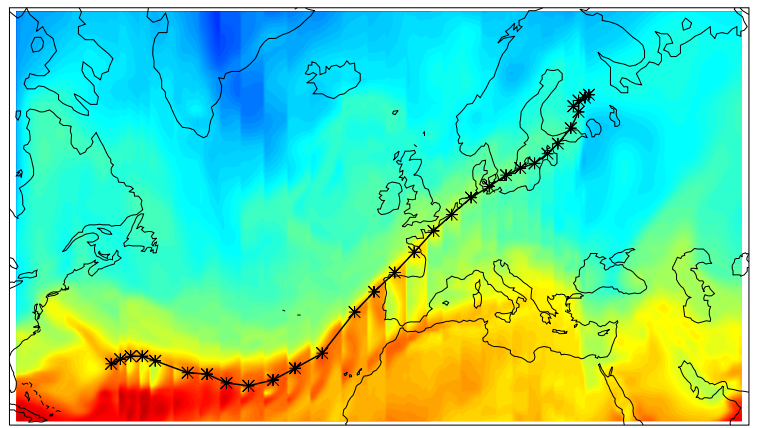

(d)

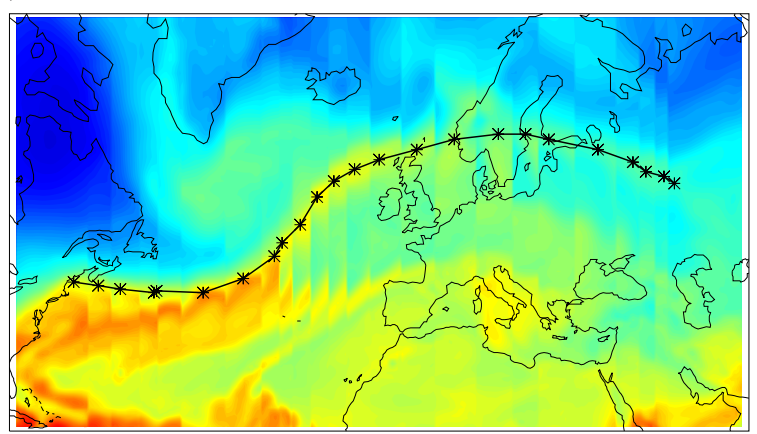

(f)

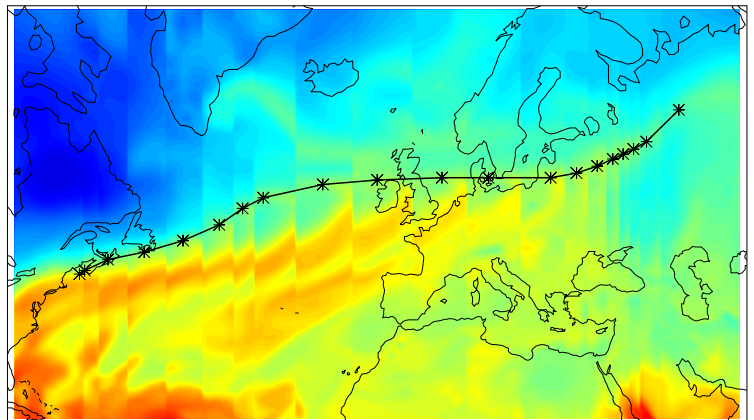

(h)

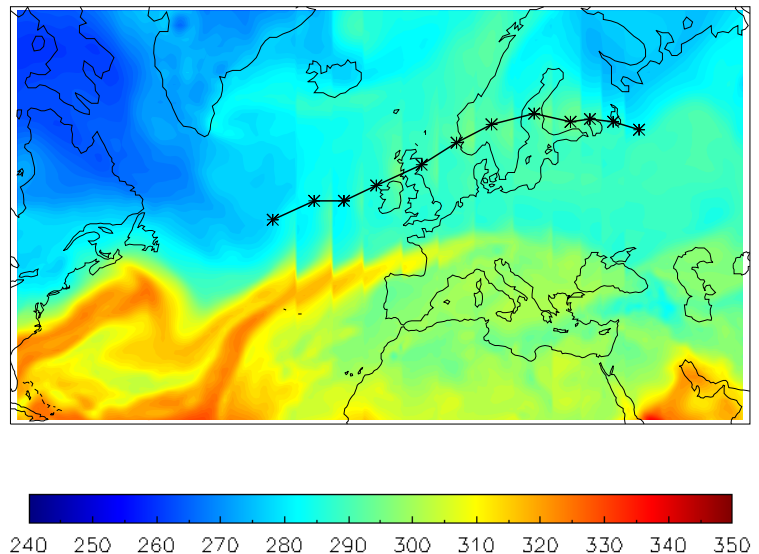

Figure 3. Examples of storm categorisation by jet stream type (a,b) storm Xynthia [split jet stream type], (c,d) Jennifer [cross late], (e,f) Kyrill [cross early], (g,h) Erwin [edge]. (left) Jet speed [total wind speed at $300 \mathrm{hPa}$ in $\mathrm{ms}^{-1}$ ] and (right) $\theta_{e}$ [calculated on the $850 \mathrm{hPa}$ surface, in K] from ERA-Interim data, using meridional slices that correspond with the track of the storm.

\subsection{Relationship to storm intensity}

If we compare the results of the storm categorisation in terms of either the jet stream or PTE given in Table 3 with storm intensity measured by the SSI values given in Table 1, no significant This article is protected by copyright. All rights reserved. link was found. This is to some extent because there are factors affecting SSI that are not related to the drivers of cyclogenesis. An example of such a factor is the wind climatology of the area over which the storm passes. If the area is prone to strong winds, the 98th percentile of the wind climatology will be high, and the SSI 


\begin{tabular}{|l|r|r|r|}
\hline & Diab & Intermediate & Horiz \\
\hline Split & 3 & 1 & 2 \\
\hline Cross late & 9 & 8 & 3 \\
\hline Cross early & 4 & 8 & 3 \\
\hline Edge & 4 & 3 & 12 \\
\hline
\end{tabular}

Table 4. Number of storms, divided into two methods of categorisation: one by dominant term in the PTE (Diab, Intermediate, Horiz), the other based on the jet stream type (Split, Cross late, Cross early, Edge). Discussion is in Section 3.3 .

\section{(1)} be relatively low for a given wind speed than in a less windprone area. Another substantial difference is that SSI responds to the wind field over a large area, whereas PTE examines the pressure field in a small area around the cyclone centre only.

For these reasons, when the correlation between SSI and minimum core pressure is tested, no correlation is found $(\mathrm{R}$ $<0.01)$. However, there is also no relationship between either method of categorisation and storm intensity measured by minimum core pressure. This indicates that diabatically-driven torms are not systematically deeper than storms where horizontal temperature advection is the main contributor towards deepening; the driving processes occur to different extents in different
situations, and so achieve a range of cyclone depths. Furthermore,
the position of the storm relative to the jet stream does not show a
Significant relationship with the intensity of the storm.

\section{Analysis of storms' forecasts}

This section examines whether the type of storm as discussed This section examines whether the type of storm as discussed
in Section 3 has a detectable impact on the forecast for the 39 Selected storms since January 1990. From the longer-term studies cited in the Introduction (Jung et al. 2006; Willison et al. 2013), it could for example be expected that storms with strong diabatic contributions may be less well forecast, because high resolution is needed to adequately represent small-scale processes such as latent heat release along fronts.

Figure 4 shows an analysis of forecast errors for the entire tracks of the 39 storms, where the zero time is fixed as the time of minimum core pressure, and the lead time is calculated relative to that time. Note that storms are not analysed after the time of the minimum pressure. Figure $4 \mathrm{a}$ and $4 \mathrm{c}$ use ECMWF operational forecasts and Figure $4 \mathrm{~b}$ and $4 \mathrm{~d}$ the control forecast from the ECMWF operational ensemble with a coarser resolution

\begin{tabular}{|l|r|r|}
\hline & Operational & Control \\
\hline Pressure & 0.41 & 0.146 \\
\hline Latitude & 0.027 & 0.081 \\
\hline Longitude & 0.129 & 0.045 \\
\hline
\end{tabular}

Table 5. Correlation coefficients for all storms' forecast quality (forecastanalysis for each quantity) compared to forecast lead time.

and Section 2.1 for details). Both Figures $4 \mathrm{a}$ and $4 \mathrm{~b}$ show a clear underestimation of the storms' strength (i.e. generally too high core pressure) for all lead times. The few data points well above the zero-bias line occur for relatively long lead times and may therefore be related to some more substantial mismatches in track. Linear regressions show an increasing under-prediction with lead time, reaching typical biases of $15 \mathrm{hPa}$ for the longest lead times, but as Table 5 indicates, the linear regression shows weak significance. Note that the linear regression is not forced to go through the origin; while this would ideally be the case, the limited amount of data means that imposing this constraint weakens the linear correlation. In terms of storm position, Figures $4 \mathrm{c}$ and $4 \mathrm{~d}$ indicate that storms are generally too far south in the forecast, because in most cases the forecast latitude is smaller than the latitude in the reanalysis. Results for longitude give a less clear signal, particularly in the operational data, but in the control forecasts the storm is generally west (lower longitude) than the storm in the analysis, indicating that the forecast storm moves too slowly. Averaged over all 39 storms, the deterministic forecasts are $2.4 \mathrm{hPa},-0.2^{\circ}$ latitude and $-0.5^{\circ}$ longitude different from the analysis at 24 hours lead time. These results are consistent with the work of Froude et al. (2007), who examined a larger set of storms including many weak storms. The results from Trzeciak et al. (2016) also indicate that storms' intensity is generally underpredicted, with a strong dependence on model resolution.

As explained in Section 2.1, the disadvantage of using operational forecast data is the inhomogeneity resulting from regular model updates and resolution increases. In order to investigate the effect of this on forecast error, the data used to generate Figure 4 were stratified into groups with identical horizontal resolution spanning $T 106$ to $T_{L} 1279$ for the operational forecasts, and $T_{L} 159$ to $T_{L} 639$ for the ensemble control forecast (Figure 5). Given that 39 storms are investigated, this creates some 


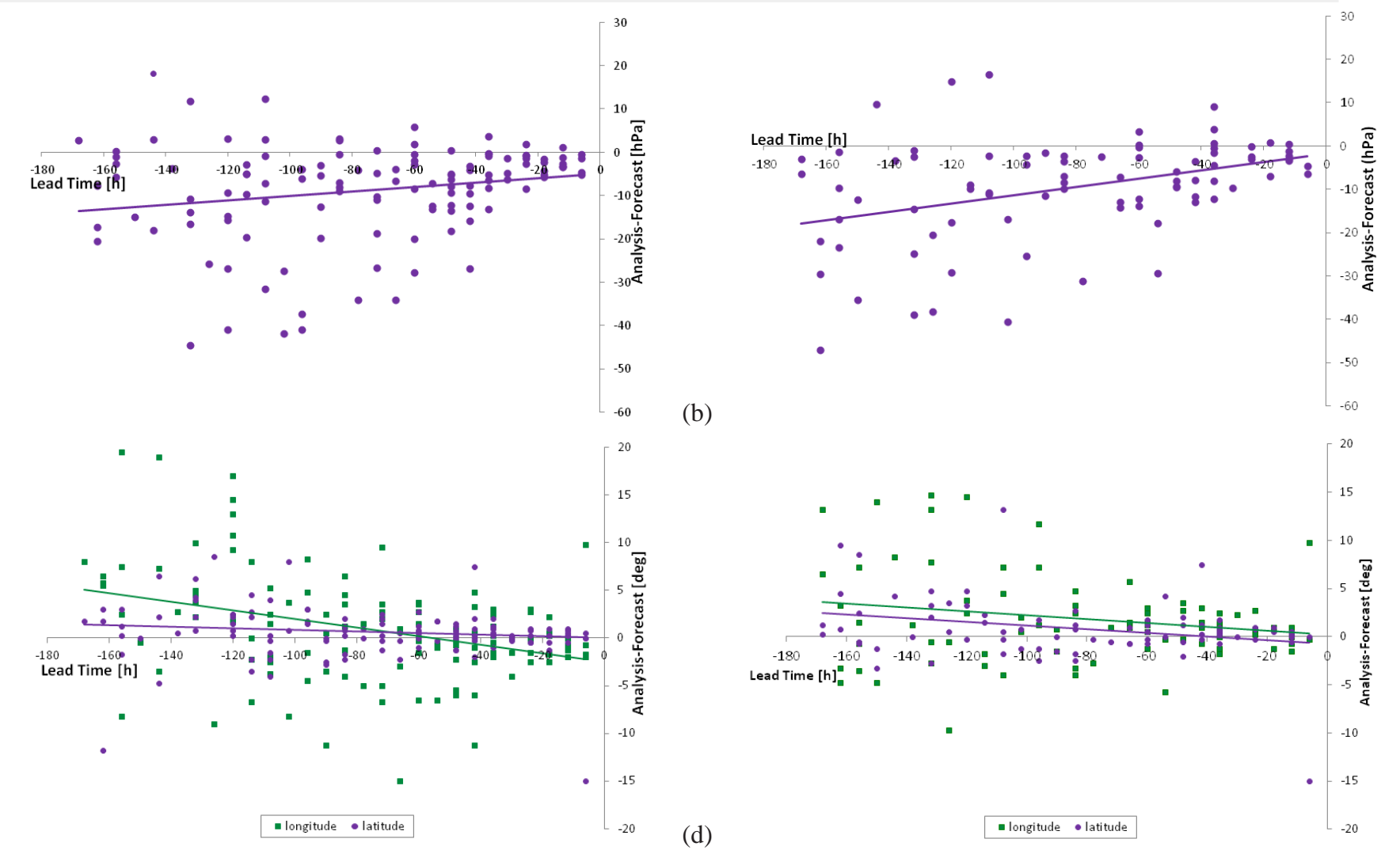

Figure 4. Difference (reanalysis—forecast) at each point along every storm's track for (a,b) core pressure and (c,d) latitude and longitude, plotted against lead time for (a,c) operational (all 39 storms listed in Table 2) and (b,d) control forecasts (28 storms after December 1997). Least square linear regression lines are shown, which were not constrained to pass through the origin.

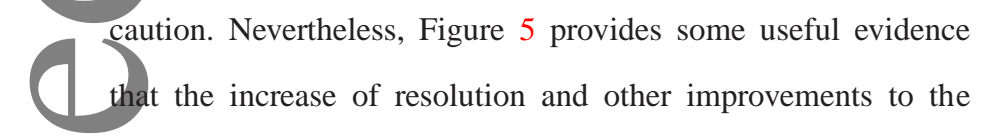
ECMWF system have generally increased the quality of the forecast. For both the deterministic and control forecasts, the oldest'model versions (T106, T213 and $T_{L} 159$ ) show the steepest regression lines, while the much higher-resolved newest versions $\left(T_{L} 1279\right.$ and $\left.T_{L} 639\right)$ show the weakest link with lead time (Figure 5). However, the results for $T_{L} 1279$ should be treated with caution, as they appear to get worse at shorter lead times, likely because there are few matched forecasts at short lead times. The intermediate versions do not show a monotonic improvement, but this could largely be due to the small numbers of storms considered here as discussed above. The correlation was also tested as per Table 5, but the results (not shown) again showed weak significance. However, comparing the operational and control forecasts to each other in Figure 4 reveals relatively small differences, indicating a moderate influence of resolution.

Figure 6 shows an analysis corresponding to Figure 4 for the entire ECMWF operational ensemble in the form of a box-and-
7. As before, we see a general under-prediction of cyclone core pressure at all lead times, and a roughly linear decrease of the negative bias (i.e. the forecasts improve linearly as forecast lead time shortens). The ensemble spread increases markedly with lead time as expected, with positive values present at all lead times, suggesting that in most cases at least some ensemble members capture the analysed strength of the storm. For lead times of 1-3 days the upper quartiles (top boundary of boxes in Figure 6) are close to zero, indicating that roughly $25 \%$ of ensemble members have an even deeper storm than analysed. The large outliers with pressure biases down to $60 \mathrm{hPa}$ are likely forecasts where the overall synoptic evolution deviates so far from the re-analysis that a matching of tracks is challenging.

The last part of this analysis is dedicated to determine whether the intensity or type of a storm has any measurable effect on its forecast. Correlations between the SSI of a storm (Table 1) and its forecast quality and ensemble spread were computed and found to be insignificant (not shown). As discussed in Section 3.3, this may be related to the strong dependence of SSI on the local climatology and large area. Stratifying storms by their jet stream type (Table erved. 
(a)

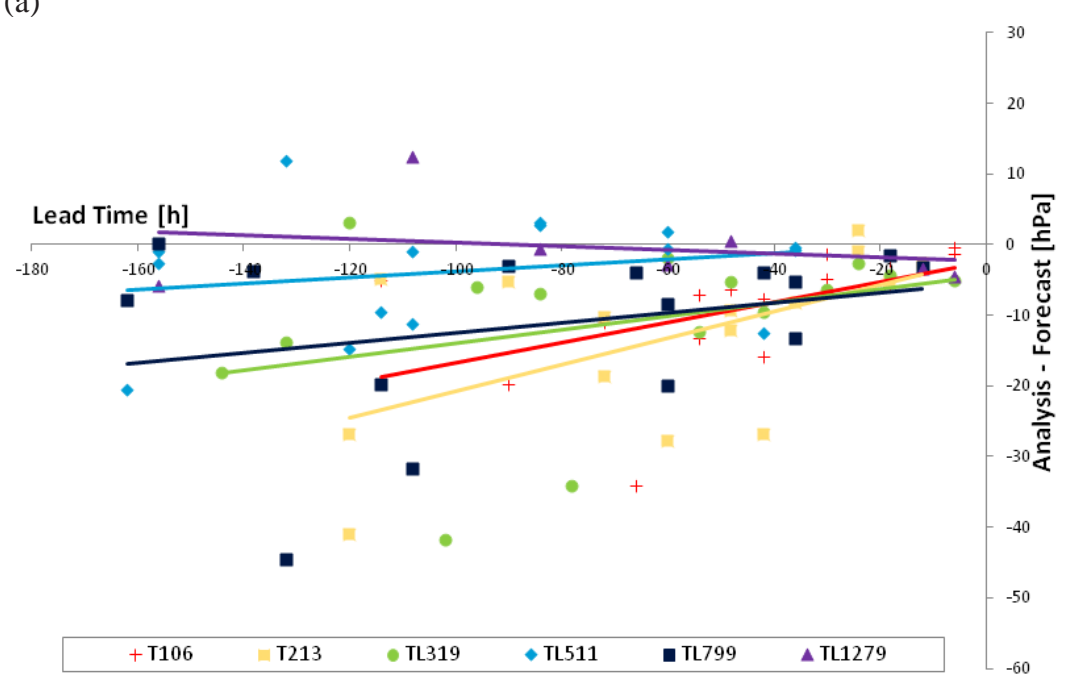

(b)
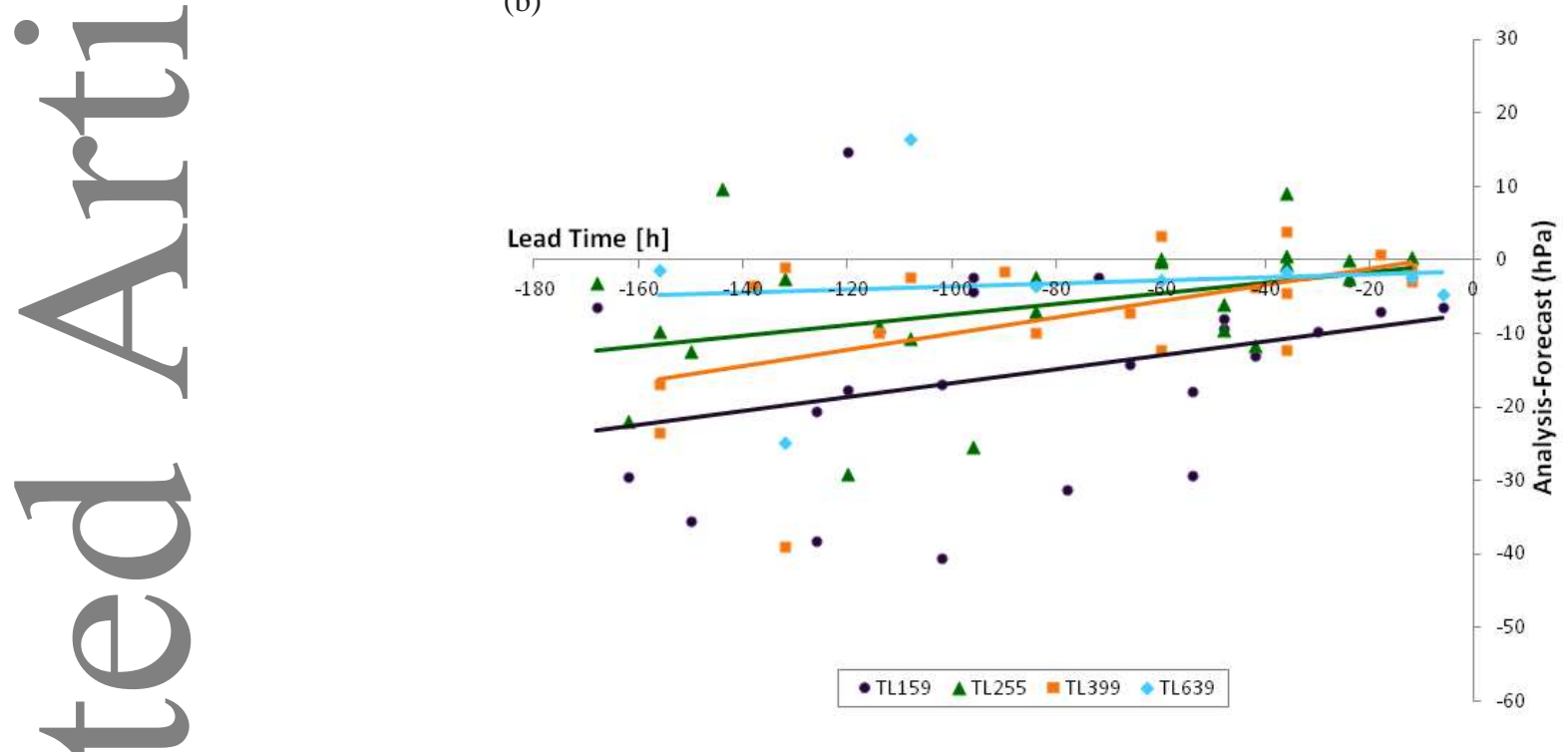

Figure 5. Core pressure difference (reanalysis—-forecast) against lead time with the storms grouped by native model resolution (Table 1), for ECMWF (a) operational (39 storms) and (b) control forecasts (28 storms). Least square linear regression lines are shown, which were not constrained to pass through the origin.

r

(1)

3 and Figure 3) also does not result in any significant differences in forecast quality or ensemble spread (not shown). One problem n this investigation is again the relatively small number of storms in some of the four jet categories that together with their uneven distribution in time and the inhomogeneity of the forecast data (Figure 5 and Table 2) made it difficult to extract a signal.

Lastly, Figure 7 shows a stratification of the data presented in Figure 4 into the three terciles of the diabres term from the PTE analysis, based on whether the horiz term, the diab term, or neither dominates the deepening of the cyclone (Table 3). Linear regression was performed and tested, to show that even in these smaller groups, the forecast quality is significantly related to lead time.

In terms of the PTE categories, surprisingly the neutral storms and ensemble control forecasts, while the horiz-type and diabtype storms are rather similar (Figure 7). So clearly, we do not find any evidence that a large contribution from diabatic sources in intense cyclones automatically leads to a worse forecast in terms of resulting core pressure, as could have been expected from more climatological studies (see discussion in Introduction). At best Figure 7a shows a larger scatter for diab-type storms, indicating that it may be more difficult to forecast these cyclones correctly, but biases can go either way. However, this behaviour is not confirmed by the ensemble control forecast shown in Figure $7 \mathrm{~b}$, although this may be because a smaller number of storms (28) are considered. Repeating this analysis for cyclone position does not result in any striking differences (not shown). Overall, these results indicate that forecast errors in cyclones depend systematically on forecast lead times due to the chaotic nature of This article is protected by copyright. All rights reserved. 


\section{References}

Ahmadi-Givi F, Craig GC, Plant RS. 2004. The dynamics of a midlatitude cyclone with very strong latent heat release. Quarterly Journal of the Royal Meteorological Society 130: 295-323.

Allen JT, Pezza AB, Block MT. 2010. Explosive cyclogenesis: A

global climatology comparing multiple reanalyses. Journal of Climate 23: 6468-6484.

Bjerknes J, Solberg H. 1922. Life cycle of the cyclones and the polar front theory of atmospheric circulation. Geophysical Publications 3: 3-17.

Boettcher M, Wernli H. 2013. A 10-yr climatology of diabatic Rossby waves in the Northern Hemisphere. Monthly Weather Review 141: 1139-1154.

Booth JF, Thompson L, Patoux J, Kelly KA. 2010. The signature of midlatitude tropospheric storm tracks in surface winds. Journal of Climate 23: 1160-1174.

Butizza R, Palmer TN. 1998. Impact of ensemble size on ensemble prediction. Monthly Weather Review 126: 2503-2518.

Dee DP, Uppala SM, Simmons AJ, Berrisford P, Poli P, Kobayashi S, Andrae U, Balmaseda MA, Balsamo G, Bauer P, Bechtold P, Beljaars ACM, van de Berg L, Bidlot J, Bormann N, Delsol C, Dragani R, Fuentes M, Geer AJ, Haimberger L, Healy SB, Hersbach H, Hólm EV, Isaksen L, Kållberg P, Köhler M, Matricardi M, McNally AP, Monge-Sanz BM, Morcrette JJ, Park BK, Peubey C, de Rosnay P, Tavolato C, Thépaut JN, Vitart F. 2011. The ERA-Interim reanalysis: configuration and performance of the data assimilation system. Quarterly Journal of the Royal Meteorological Society 137: 553-597.

Eady ET. 1949. Long wave and cyclone waves. Tellus 1(3): 33-52. Emanuel K, Fantini M, Thorpe A. 1987. Baroclinic instability in an environment of small stability to slantwise moist convection.

Part I: Two-dimensional models. Journal of the Atmospheric Sciences 44: 1559-1573.

Fink AH, Bruecher T, Ermert V, Krueger A, Pinto JG. 2009. The European storm Kyrill in January 2007: synoptic evolution, meteorological impacts and some considerations with respect to climate change. Natural Hazards and Earth System Sciences 9(2): 405-423.

This article is protected by copyright. All rights reserved.
Fink AH, Pohl S, Pinto J, Knippertz P. 2012. Diagnosing the influence of diabatic processes on the explosive deepening of extra-tropical cyclones. Geophysical Research Letters 39: L07 803.

Froude LSR. 2009. Regional differences in the prediction of extratropical cyclones by the ECMWF Ensemble Prediction System. Monthly Weather Review 137: 893-911.

Froude LSR, Bengtsson L, Hodges KI. 2007. The predictability of extratropical storm tracks and the sensitivity of their prediction to the observing system. Monthly Weather Review 135: 315333.

Goyette S, Beniston M, Caya D, Laprise R, Jungo P. 2001. Numerical investigation of an extreme storm with the canadian regional climate model: the case study of windstorm Vivian, Switzerland, February 27, 1990. Climate Dynamics 18 (1-2): $145-168$.

Guha-Sapir D, Below R, Hoyois P. 2015. Emdat - the international disaster database. URL: www.emdat.be.

Jung T, Gulev SK, Rudeva I, Soloviov V. 2006. Sensitivity of extratropical cyclone characteristics to horizontal resolution in the ECMWF model. Quarterly Journal of the Royal Meteorological Society 132: 1839-1857.

Klawa M, Ulbrich U. 2003. A model for the estimation of storm losses and the identification of severe winter storms in Germany. Natural Hazards and Earth System Sciences 3: 725732.

Knippertz P, Fink AH, Pohle S. 2009. Reply. Monthly Weather Review 137: 3151-3157.

Knippertz P, Wernli H. 2010. A Lagrangian climatology of tropical moisture exports to the Northern Hemispheric extratropics. Journal of Climate 23: 987-1003.

Leckebusch G, Renggli D, UUlbrich. 2008. Development and application of an objective storm severity measure for the northeast Atlantic region. Meteorologische Zeitschrift 17(5): $575-587$.

Liberato MLR, Pinto JG, Trigo IF, Trigo RM. 2011. Klaus an exceptional winter storm over northern Iberia and southern France. Weather 66: 330-334. 
Liberato MLR, Pinto JG, Trigo RM, Ludwig P, nez PO, Yuen D,

Trigo IF. 2013. Explosive development of winter storm Xynthia over the subtropical North Atlantic Ocean. Natural Hazards and Earth System Sciences 13: 2239-2251.

Ludwig P, Pinto JG, Hoepp SA, Fink AH, Gray SL. 2015. Secondary cyclogenesis along an occluded front leading to damaging wind gusts: windstorm Kyrill, January 2007. Monthly

Weather Review 143: 1417-1437.

Ludwig P, Pinto JG, Reyers M, Gray SL. 2014. The role of anomalous SST and surface fluxes over the southeastern North Atlantic in the explosive development of windstorm Xynthia.

Quarterly Journal of the Royal Meteorological Society 140: 1729-1741.

Moore RW, Montgomery MT. 2004. Re-examining the dynamics of short-scale, diabatic Rossby waves and their role in midlatitude moist cyclogenesis. Journal of the Atmospheric Sciences 61: 754-768.

Moore RW, Montgomery MT. 2005. Analysis of an idealized, three-dimensional diabatic Rossby vortex: a coherent structure of the moist baroclinic atmosphere. Journal of the Atmospheric Sciences. 62: 2703-2725.

Munich Re NatCatSERVICE. 2015. 10 costliest winter storms in europe 1980-2014.

Naud CM, Booth JF, Genio ADD. 2014. Evaluation of ERAInterim and MERRA cloudiness in the southern ocean. Journal of Climate 27: 2109-2124.

Naud CM, Genio ADD, Bauer M. 2006. Observational constraints on the cloud thermodynamic phase in midlatitude storms. Journal of Climate 19: 5273-5288.

Odell L, Knippertz P, Pickering S, Parkes B, Roberts A. 2013. The braer storm revisited. Weather 68 (4): 105-111.

Office for National Statistics. 2011. Consumer price indices 19882015.

Parker DJ, Thorpe AJ. 1995. Conditional convective heating in a baroclinic atmosphere: a model of convective frontogenesis. Journal of the Atmospheric Sciences 52: 1699-1711.

Posselt DJ, Martin JE. 2004. The effect of latent heat release on the evolution of a warm occluded thermal structure. Monthly Weather Review 132: 578-599.
Rees DG. 2001. Essential statistics. Chapman \& Hall / CRC, 4th edn.

Rivière G, Arbogast P, Joly A. 2015. Eddy kinetic energy redistribution within windstorms Klaus and Friedhelm. Quarterly Journal of the Royal Meteorological Society. 141: 925-938.

Rivière G, Arbogast P, Lapeure G, Maynard K. 2012. A potential vorticity perspective on the motion of a midlatitude winter storm. Geophysical Research Letters 39: L12 808.

Rivière G, Arbogast P, Maynard K, Joly A. 2010. The essential ingredients leading to the explosive growth stage of the European wind storm Lothar of Christmas 1999. Quarterly Journal of the Royal Meteorological Society 136: 638-652.

Rivière G, Joly A. 2006a. Role of low-frequency deformation field on the explosive growth of extratropical cyclones at the jet exit. Part I: Barotropic critical region. Journal of the Atmospheric Sciences 63: 1965-1981.

Rivière G, Joly A. 2006b. Role of low-frequency deformation field on the explosive growth of extratropical cyclones at the jet exit. Part II: Baroclinic critical region. Journal of the Atmospheric Sciences 63: 1982-1995.

Sampe T, Xie SP. 2007. Mapping high sea winds from space. Bulletin of the American Meteorological Society 88: 19651978.

Stoelinga MT. 1996. A potential vorticity-based study of the role of diabatic heating and friction in a numerically simulated baroclinic cyclone. Monthly Weather Review 124: 849-874.

Trzeciak T, Knippertz P, Pirret JSR, Williams KD. 2016. Can we trust climate models to realistically represent severe European windstorms? Climate Dynamics 46: 3431-3451.

Vaughan G, Methven J, Anderson D, Antonescu B, Baker L, Baker TP, Ballard SP, Bower KN, Brown PRA, Chagnon J, Choularton TW, Chylik J, Connolly PJ, Cook PA, Cotton RJ, Crosier J, Dearden C, Dorsey JR, Frame THA, Gallagher MW, Goodliff M, Gray SL, Harvey BJ, Knippertz P, Lean HW, Li D, Lloyd G, Martnez-Alvarado O, Nicol J, Norris J, Öström E, Owen J, Parker DJ, Plant RS, Renfrew IA, Roberts NM, Rosenberg P, Rudd AC, Schultz DM, Taylor JP, Trzeciak T, Tubbs R, Vance AK, van Leeuwen PJ, Wellpott A, Woolley A. 2014. Cloud banding and winds in intense European cyclones:

This article is protected by copyright. All rights reserved. 
Results from the DIAMET project. Bulletin of the American Meteorological Society 96: 249265.

Čampa J, Wernli H. 2012. A PV perspective on the vertical structure of mature midlatitude cyclones in the Northern Hemisphere. Journal of the Atmospheric Sciences 69: 725-740.

Wang CC, Rogers JC. 2001. A composite study of explosive cyclogenesis in different sectors of the north Atlantic. Part I: cyclone structure and evolution. Monthly Weather Review 129: 1481-1499.

Wernli H, Dirren S, Liniger MA, Zillig M. 2002. Dynamical aspects of the winter storm 'Lothar' (24-26 December 1999). Quarterly Journal of the Royal Meteorological Society 128: $405-429$.

Whitaker J, Davis C. 1994. Cyclogenesis in a saturated environment. Journal of the Atmospheric Sciences 51: 889-907. Willison J, Robinson WA, Lackmann GM. 2013. The importance of resolving mesoscale latent heat in the North Atlantic storm track. Journal of the Atmospheric Sciences 70: 2234-2250.

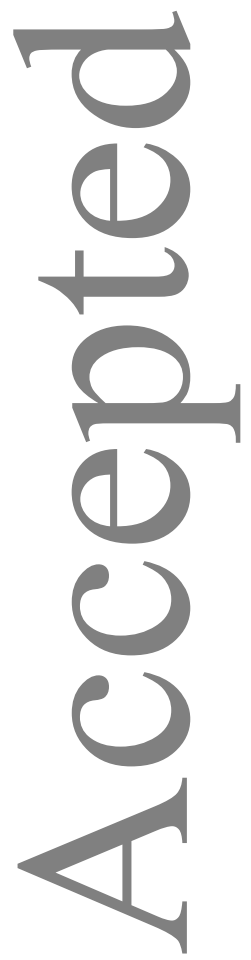

This article is protected by copyright. All rights reserved. 